\title{
Land Urbanization Level of Core Cities in the Silk Road Economic Belt
}

\author{
LI Zhe ${ }^{\mathrm{a},{ }^{*},}$ SUI Dangchen ${ }^{\mathrm{b}}$ \\ International Business School of Shaanxi Normal University, China \\ a snnulizhe@snnu.edu.cn, b suihu7672@snnu.edu.cn
}

Keywords: Land urbanization level, Silk Road Economic Belt, Evaluation system.

\begin{abstract}
With the construction and development of the Silk Road Economic Belt, it is of great significance to analyze the land urbanization level of cities along the route. This paper established a new evaluation system, consisting of 11 indexes from 6 aspects, to measure the land urbanization level of 71 core cities in the Silk Road Economic Belt in 2014.The Principal component analysis (PCA) method was used to determine weight of indexes and get calculation results. In the course of these studies, it is visually apparent that spatial differentiation phenomena and unbalanced development exist both in provincial scale and urban scale. To promote sustainable development of Silk Road Economic Belt, enhancing the top design, improving the evaluation system, strengthening the cooperation and handling the relationship between exploitation and protection of resources are considered effective methods.
\end{abstract}

\section{Introduction}

The concept of Silk Road Economic Belt was firstly proposed by the president Xi Jinping in 2013, which was based on the well-known Old Silk Road in history and expected to make great contribution to deeper cooperation between Eurasian countries in future. It is of great significance to construct Silk Road Economic Belt, regarded as one of the important ways to strengthen regional economic cooperation, accelerate world economic development and optimize China's layout of city and population [1]. Undoubtedly, Intensive urbanization process is happening in China, promoting the urban land expansion, transition of economic structure and population migration, which has become a hot research area. Under the background of rapid urbanization, the concept of land urbanization has been proposed as a new object of study and considered as a main component section of urbanization process. In recent years, the accelerated speed of land urbanization has been much faster than population urbanization in China [2], leading to a range of issues such as land finance, chaotic urban layout, land devaluation, and land wastage [3].In order to monitor the change of land urbanization, a lot of researches concentrated on the analyses of land urbanization, including measurement, evaluation, spatial-temporal differences and driving forces. Studies, which revealed that land urbanization level in the coastal areas of eastern China is much higher than that in center and western China [4], showed the imbalance of urban development, and urban population agglomeration, industrial growth and investment were believed three drivers [5]. Even through attention has been paid to the sustainable development ability, competitive capacity and urbanization development of cities along the Silk Road Economic Belt, few studies attempted to combine the Silk Road Economic Belt research with land urbanization of cities.

In this paper, we first selected 71 core cities from 9 provinces and municipalities in the Silk Road Economic Belt as representatives to measure the land urbanization level in 2014 on the basis of establishing the evaluation system, and analyzed the influencing factors. Finally, the policy countermeasures and proposals were provided in the rest of the paper. The aim of this paper is attempting to establish a new evaluation system of land urbanization, grasp the situation of urban land use in the Silk Road Economic Belt and develop the Silk Road Economic Belt research, which is of theoretical and practical importance. 


\section{Data and methods}

2.1 Data sources. There are 9 provinces and municipalities contained in the Silk Road Economic Belt (Shaanxi, Gansu, Qinghai, Ningxia, Xinjiang, Chongqing, Sichuan, Yunnan and Guangxi), thus we chose all the 8 vice-provincial cities, 62 prefecture-level cities and 1 municipality for the research respectively, except Hechi because of data incompleteness. The data were gathered from the following sources: China City Statistical Yearbook 2015 and Provincial Statistical Yearbook 2015.

2.2 Evaluation system. After the summarization of present literatures, the evaluation index system of land urbanization level mainly included land structure, landscape, capital input and economic benefit [6].On the basis of existing research and experience, a new evaluation system was established from 6 perspectives. Land use structure shows the development degree of urban land. Economic input and output are used to estimate the economic value that urban land plays. Population-supporting capacity indicates the relation between urban land and urban population. Social service represents the capacity of basic services that urban land provides. And ecological environment is used to evaluate the quality of human settlement.

The evaluation system of land urbanization level is shown in Table 1.

Table 1. Evaluation system of land urbanization level

\begin{tabular}{llll}
\hline Layer of target & \multicolumn{1}{c}{ Layer of factors } & Code & \multicolumn{1}{c}{ Layer of indexes } \\
\hline Land urbanization level & Land use structure & $\mathrm{X}_{1}$ & Urban construction land ratio \\
& Economic input & $\mathrm{X}_{2}$ & Fixed-asset investment per unit area \\
& & $\mathrm{X}_{3}$ & Public finance expenditure per unit area \\
& Economic output & $\mathrm{X}_{4}$ & GDP per unit area \\
& Population-supporting capacity & $\mathrm{X}_{6}$ & Public finance income per unit area \\
& & $\mathrm{X}_{7}$ & Population density \\
& Social service & $\mathrm{X}_{8}$ & Educational institutions per unit area \\
& & $\mathrm{X}_{9}$ & Medical institutions per unit area \\
& Ecological environment & $\mathrm{X}_{10}$ & Green coverage ratio \\
& & $\mathrm{X}_{11}$ & Industrial solid wastes comprehensively \\
\hline
\end{tabular}

Note: Educational institutions include regular institutions of higher education, vocational secondary schools, regular secondary schools and primary schools. Medical institutions include hospitals and health centers.

2.3 Index weight setting and measurement. Principal component analysis (PCA) was used for measure the land urbanization level, which demanded data normalization with the purpose of eliminating the differences caused by magnitude and measurement units. The method of data normalization is z-score, making sure each column of data with zero mean and unit variance, of which formula is expressed as

$$
Z_{\mathrm{ij}}=\frac{X_{\mathrm{ij}}-\overline{X_{j}}}{S_{j}}
$$

where $Z_{\mathrm{ij}}$ represents each normalization data, $X_{\mathrm{ij}}$ is each original data, $\bar{X}_{j}$ is mean value of indexes, $S_{\mathrm{j}}$ represents standard deviation of each index, $\mathrm{i}$ is the number of evaluation objects and $\mathrm{j}$ is the number of indexes. In this paper, a KMO inspection and Bartlett test of sphericity were conducted to test the correlation of the data, and the analysis results are shown in Table 2.

Table 2. KMO and Bartlett's Test

\begin{tabular}{lll}
\hline Kaiser-Meyer-Olkin Measure of Sampling Adequacy & 0.845 \\
Bartlett's Test of Sphericity & Approx.Chi-Square & 1023.927 \\
& df & 55 \\
& Sig. & 0.000 \\
\hline
\end{tabular}


The KMO is greater than 0.8, and Bartlett's inspection gives the probability of the sphere as 0.000 , less than the significance level 0.05 , which indicates that the data is suitable for such an analysis. Based on the above analysis, PCA results are shown below.

Table 3. Total variance explained

\begin{tabular}{|c|c|c|c|c|c|c|c|c|c|}
\hline \multirow{2}{*}{$\begin{array}{c}\text { Componen } \\
\mathrm{t}\end{array}$} & \multicolumn{3}{|c|}{ Initial Eigenvalues } & \multicolumn{3}{|c|}{$\begin{array}{c}\text { Extraction Sums of Squared } \\
\text { Loadings }\end{array}$} & \multicolumn{3}{|c|}{$\begin{array}{c}\text { Rotation Sums of Squared } \\
\text { Loadings }\end{array}$} \\
\hline & Total & $\begin{array}{c}\% \text { of } \\
\text { Variance }\end{array}$ & $\begin{array}{c}\text { Cumulative } \\
\%\end{array}$ & Total & $\begin{array}{c}\% \text { of } \\
\text { Variance }\end{array}$ & $\begin{array}{c}\text { Cumulative } \\
\%\end{array}$ & Total & $\begin{array}{c}\% \text { of } \\
\text { Variance }\end{array}$ & $\begin{array}{c}\text { Cumulative } \\
\%\end{array}$ \\
\hline $\mathrm{X}_{1}$ & 6.820 & 62.002 & 62.002 & 6.820 & 62.002 & 62.002 & 6.219 & 56.536 & 56.536 \\
\hline $\mathrm{X}_{2}$ & 1.355 & 12.321 & 74.323 & 1.355 & 12.321 & 74.323 & 1.638 & 14.894 & 71.430 \\
\hline $\mathrm{X}_{3}$ & 1.021 & 9.286 & 83.608 & 1.021 & 9.286 & 83.608 & 1.340 & 12.179 & 83.608 \\
\hline $\mathrm{X}_{4}$ & 0.688 & 6.254 & 89.862 & & & & & & \\
\hline $\mathrm{X}_{5}$ & 0.613 & 5.571 & 95.433 & & & & & & \\
\hline $\mathrm{X}_{6}$ & 0.186 & 1.687 & 97.120 & & & & & & \\
\hline $\mathrm{X}_{7}$ & 0.162 & 1.476 & 98.596 & & & & & & \\
\hline $\mathrm{X}_{8}$ & 0.057 & 0.516 & 99.113 & & & & & & \\
\hline $\mathrm{X}_{9}$ & 0.053 & 0.479 & 99.592 & & & & & & \\
\hline $\mathrm{X}_{10}$ & 0.030 & 0.269 & 99.861 & & & & & & \\
\hline $\mathrm{X}_{11}$ & 0.015 & 0.139 & 100.000 & & & & & & \\
\hline
\end{tabular}

The results show that the 11 traits are consolidated into 3 principal components which account for $83.608 \%$ of total variation. On the basis of calculation of eigenvector, standardized data and formula, land urbanization level of 71 core cities was measured and sequenced (Table 4). The positive value indicates that land urbanization level of the city is higher than the average level, while a negative one represents a lower level.

Table 4. Land urbanization level of 71 core cities

\begin{tabular}{|c|c|c|c|c|c|c|c|c|}
\hline Ranking & City & Level & Ranking & City & Level & Ranking & City & Level \\
\hline 1 & Chengdu & 3.833 & 25 & Guigang & 0.031 & 49 & Kelamayi & -0.366 \\
\hline 2 & $\mathrm{Xi}^{6}$ an & 3.003 & 26 & Tongchuan & -0.048 & 50 & Haidong & -0.367 \\
\hline 3 & Zigong & 0.822 & 27 & Leshan & -0.066 & 51 & $\begin{array}{c}\text { Guangyua } \\
n\end{array}$ & -0.378 \\
\hline 4 & Beihai & 0.768 & 28 & Qinzhou & -0.099 & 52 & Hezhou & -0.380 \\
\hline 5 & Chongqing & 0.749 & 29 & Liuzhou & -0.106 & 53 & Shangluo & -0.384 \\
\hline 6 & Deyang & 0.731 & 30 & Panzhihua & -0.109 & 54 & Dingxi & -0.391 \\
\hline 7 & Xianyang & 0.711 & 31 & Longnan & -0.140 & 55 & $\mathrm{Ya}^{6}$ an & -0.409 \\
\hline 8 & Neijiang & 0.634 & 32 & Baoji & -0.151 & 56 & Laibin & -0.410 \\
\hline 9 & Suining & 0.565 & 33 & Fangcheng-gang & -0.168 & 57 & Baoshan & -0.429 \\
\hline 10 & Kunming & 0.534 & 34 & Mianyang & -0.172 & 58 & Yulin & -0.454 \\
\hline 11 & Wulumuqi & 0.463 & 35 & Wuzhou & -0.174 & 59 & Chongzuo & -0.464 \\
\hline 12 & Weinan & 0.409 & 36 & Bazhong & -0.182 & 60 & Baise & -0.500 \\
\hline 13 & Guan'gan & 0.393 & 37 & Wuwei & -0.209 & 61 & Qingyang & -0.508 \\
\hline 14 & Yinchuan & 0.370 & 38 & Tianshui & -0.213 & 62 & Ankang & -0.516 \\
\hline 15 & Nanchong & 0.368 & 39 & Shizuishan & -0.214 & 63 & Jinchang & -0.525 \\
\hline 16 & Ziyang & 0.304 & 40 & Jiayuguan & -0.227 & 64 & Baiyin & -0.531 \\
\hline 17 & Xining & 0.237 & 41 & Pingliang & -0.251 & 65 & Yan'an & -0.548 \\
\hline 18 & Lanzhou & 0.235 & 42 & Hanzhong & -0.259 & 66 & Lincang & -0.552 \\
\hline 19 & Meishan & 0.233 & 73 & Zhaotong & -0.268 & 67 & Zhongwei & -0.618 \\
\hline 20 & Nanning & 0.170 & 44 & Wuzhong & -0.273 & 68 & Zhangye & -0.628 \\
\hline 21 & Yulin & 0.154 & 45 & Qujing & -0.284 & 69 & Lijiang & -0.638 \\
\hline 22 & Dazhou & 0.116 & 46 & Guyuan & -0.302 & 70 & $\mathrm{Pu}$ 'er & -0.660 \\
\hline 23 & Luzhou & 0.091 & 47 & Yuxi & -0.308 & 71 & Jiuquan & -0.761 \\
\hline 24 & Yibin & 0.063 & 48 & Guilin & -0.344 & & & \\
\hline
\end{tabular}

\section{Results}

It can be concluded that only 25 cities of the total take a higher land urbanization level than the average level, which shows obvious characteristics of spatial differentiation. Vice-provincial cities, the provincial capital cities, have the highest land urbanization level in each province, except 
Nanning. It's not surprising to find this result, because funds, population, resources and technologies, attracted by the provincial capital cities, effectively promote the land urbanization process. Meanwhile, the land urbanization level of Chongqing municipality is higher than any other provinces' average level, and cities with a high level of land urbanization are centrally distributed in such provinces as Sichuan, Shaanxi and Xinjiang, while other backward regions mainly locate in Qinghai, Ningxia, Yunnan and Gansu. Through analysis, a significant spatial differentiation of land urbanization level is found both in provincial scale and in urban scale in 2014, reflecting regional development distinctions in economy, finance, industry, urbanization and land use.

\section{Conclusions}

To sum up, land urbanization is a significant aspect of urbanization and land use, playing an essential role in the development of Silk Road Economic Belt. On the basis of existing research and experience, land use structure, economic input, economic output, population-supporting capacity, social service and ecological environment were considered the factors to evaluate land urbanization, and 11 specific indexes were selected to measure the land urbanization level. Through establishing the evaluation system, this paper evaluated the land urbanization level of core cities in the Silk Road Economic Belt, using the cross-sectional data of 71 cities in 2014, and principal component analysis was employed as the main research method. The results indicated the unbalanced development of land urbanization among selected provinces, which needs further research and policy support.

To promote the function of Silk Road Economic Belt, the government's primary task is to get to grips with the land urbanization. First, the top design of land urbanization should be enhanced. Depending on the diverse development situations, phased and targeted policies would take effect in different regions, therefore, it's an effective method to improve the land urbanization level and eliminate the gap between developed and backward cities by establishing perfect policies and rules. Second, the evaluation system of land urbanization level should be improved. Compared with evaluation system of urbanization, evaluation system of land urbanization has not been paid enough attention, leading to a lack of complete understanding and profound recognition about land urbanization, which makes an objective and scientific evaluation system urgently needed. Third, the cooperation among provinces and cities should be strengthened. Although the financial cooperation has gained an initial scale and scientific cooperation in major projects has scored remarkable achievements [7], achievement of intergovernmental cooperation has not come to arise, which is supposed to maximize efficiency and drive improvements in land urbanization. Forth, the relationship between exploitation and protection of resources should be well handled. Only by reducing the adverse phenomena such as excessive occupation of cultivated land and waste of construction land, can land urbanization in Silk Road Economic Belt achieve sustainable development.

Despite the present results and proposals have been involved in this paper, land urbanization level of core cities in the Silk Road Economic Belt remains to be further studied.

\section{References}

[1] Bai Y, Wang S. Deep Background and Geopolitical Strategy of Silk-road Economic Belt [J]. Reform, 2014(3):64-73. (in Chinese)

[2] Da-Dao L U, Yao S M. A SCIENTIFIC THOUGHT ABOUT URBANIZATION PROGRESS IN CHINA [J]. Human Geography, 2007(4):1-5. (in Chinese)

[3] Li T. URBANIZATION OF LAND IN URBANIZATION PROCESS OF CHINA:BOON OR BANE? [J]. City Planning Review, 2011, v.35;No.280(2):11-12. (in Chinese)

[4] Yang Y,Ma X,Wang C. THE SPATIAL-TEMPORAL DYNAMICS OF THE LAND URBANIZATION LEVEL IN CHINA BASED ON NIGHTTIME LIGHT DATA [J]. Human Geography, 2015(5):91-98. (in Chinese) 
[5] Lin X, Wang Y, Wang S, et al. Spatial differences and driving forces of land urbanization in China[J]. Journal of Geographical Sciences, 2015, 25(5):545-558.

[6] Ping LV, Tao Z, Zheng-Feng Z, et al. Construction and Application of Land Urbanization and Corresponding Measurement Index System[J]. China Land Science, 2008, 22(8):24-31. (in Chinese)

[7] Zhang Z, Pu Z. Conforming to the Trend at An Appropriate Time-My Thoughts on the Building of the Silk Road Economic Belt[J]. International Understanding, 2013(4):6-8. 